University of Nebraska - Lincoln

DigitalCommons@University of Nebraska - Lincoln

\title{
Tree size but not forest basal area influences ant colony response to disturbance in a neotropical ant-plant association
}

Thomas S. Davis

USDA Agricultural Research Service, Yakima Agricultural Research Laboratory, tsdavis1@gmail.com

Nathaniel E. Foote

USDA Agricultural Research Service, Yakima Agricultural Research Laboratory

Kevin C. Grady

USDA Agricultural Research Service, Yakima Agricultural Research Laboratory

Follow this and additional works at: https://digitalcommons.unl.edu/usdaarsfacpub

Davis, Thomas S.; Foote, Nathaniel E.; and Grady, Kevin C., "Tree size but not forest basal area influences ant colony response to disturbance in a neotropical ant-plant association" (2012). Publications from USDA-ARS / UNL Faculty. 1490.

https://digitalcommons.unl.edu/usdaarsfacpub/1490

This Article is brought to you for free and open access by the U.S. Department of Agriculture: Agricultural Research Service, Lincoln, Nebraska at DigitalCommons@University of Nebraska - Lincoln. It has been accepted for inclusion in Publications from USDA-ARS / UNL Faculty by an authorized administrator of DigitalCommons@University of Nebraska - Lincoln. 


\title{
Tree size but not forest basal area influences ant colony response to disturbance in a neotropical ant-plant association
}

\author{
Thomas S. Davis*, Nathaniel E. Foote and Kevin C. Grady \\ USDA Agricultural Research Service, Yakima Agricultural Research \\ Laboratory, 5230 Konnowac Pass Road, Wapato, WA 98951, USA
}

(Accepted 30 March 2012; First published online 11 May 2012)

\begin{abstract}
Ant-acacia mutualisms are conspicuous biotic associations in Savannah and neotropical ecosystems; however, the effects of tree size and forest structure on ant behaviour and tree traits are rarely examined. We tested two hypotheses related to these effects: (1) ant responses to disturbance are influenced by tree size and forest basal area; and (2) tree traits important to ants are predictable by tree size and forest basal area. We investigated these hypotheses in a dry tropical forest (Ometepe Island, Nicaragua) with the myrmecophytic Collins acacia (Vachellia collinsii Saff.) and the ant Pseudomyrmex spinicola (Emery 1890). We measured trees from three size classes and three basal area classes and quantified resources that are important for ants, including food resources (nectaries and Beltian bodies) and domiciles (thorns), as well as a measure of potential tree reproductive fitness (seedpods). We also evaluated ant responses to experimental disturbances. Three important findings emerged: (1) on average, $1140-1173 \%$ more ants responded to experimental disturbances of large trees than small- or intermediate-sized trees, respectively; (2) forest basal area did not affect ant responses to disturbance; and (3) neither tree size nor forest basal area was correlated with branch-level mean numbers of nectaries, food bodies or thorns. Our studies support the hypothesis that tree size is an important factor regarding ant behavioural responses to disturbance, but not forest basal area. Our work suggests that future studies of ant behaviour on myrmecophytes should consider tree size.
\end{abstract}

Key words: acacia, ants, basal area, functional traits, mutualism, myrmecophyte, Pseudomyrmex spinicola, Vachellia collinsii (Acacia)

\section{Introduction}

Tropical and neotropical ant-acacia systems have emerged as an important study system for testing mutualism theory (Bronstein, 1998; Heil and McKey, 2003), and the ecology of ant-acacia mutualisms in Central America has been of significant interest to biologists for over 50 years (Janzen, 1966). Typically, trees promote the colonization of ant species by

*E-mail: tsdavis1@gmail.com producing extrafloral nectaries (Barton, 1986) and nutritious food bodies (Beltian bodies; Belt, 1874), in addition to swollen thorns which ant colonies inhabit (domatia; Fonseca, 1993). In return, acacia trees are aggressively defended from herbivory by resident ant colonies (Beattie, 1985), and there is often fierce competition between ant colonies for access to acacia tree resources (Davidson et al., 1989; Palmer, 2003). Many plant species are known to associate with ants in tropical regions (e.g. Cecropia spp. (Urticaceae), Leonardoxa spp. (Fabaceae), etc.; 
Janzen, 1973; Gaume and McKey, 1999), and antassociated plants have been termed 'myrmecophytes'. Although the interaction between ants and myrmecophytes is considered largely obligate in several associations (Bronstein, 1998), tree traits are thought to ultimately promote and maintain the persistence of the mutualism through time (Willmer and Stone, 1997; Palmer et al., 2008).

In an African myrmecophyte, herbivory has been shown to be an ecological factor that mediated the functionality and distribution of tree traits important to the mutualism (e.g. number of swollen thorns, number of nectaries; Palmer et al., 2008). When browsing pressure from large ungulates was reduced, trees gradually senesced traits that facilitated inhabitation by ants (Palmer et al., 2008). However, locally heterogeneous environmental conditions can also regulate the expression of tree traits (Agyeman, 1994; Poorter, 1999; Rosati et al., 1999). The density of woody plant species may be an especially important aspect of the local environment. Basal area is an easily measured environmental variable that describes the crosssectional area of woody plants per unit area, and is a convenient surrogate measure of tree biomass in neotropical forests (Phillips et al., 1998). Forest basal area is correlated with numerous environmental factors, including thermal variability (D'Souza et al., 2011), water and nutrient availability (Bergh et al., 1999), light regime (Montgomery and Chazdon, 2001), and tree competition (Bella, 1971). These relationships make basal area a useful and broadly informative measurement regarding correlated environmental variables, tree biomass and microsite conditions (Phillips et al., 1998). While antacacia systems have been studied across environmental gradients (Rico-Gray et al., 1998), the effects of tree size and forest basal area on ant behaviours and tree traits are rarely explored (but see Agrawal, 1998).

Here, we ask the question 'Does myrmecophyte size or forest structure influence ant behaviours or functional tree traits?' To investigate this question, we tested two hypotheses: (1) ant responses to tree disturbance vary across gradients of tree size and forest basal area; and (2) tree traits that affect ant behaviours vary across these gradients. We tested these hypotheses by extensively surveying the morphology of the myrmecophytic Collins acacia (V. collinsii Saff. (Fabaceae), formerly Acacia collinsii) inhabited by the ant P. spinicola Emery (Hymenoptera: Formicidae), and evaluating ant behaviours with simple experimental disturbances. We found that, on average, ants tended to respond to experimental disturbances in dramatically higher abundances when large trees were disturbed, and most tree traits were consistently distributed across tree size classes and forest basal area classes.
Our findings have implications for studies of ant behaviours in neotropical ant-plant associations, and we suggest that myrmecophyte size may be an important factor to consider in future work.

\section{Materials and methods}

\section{Study system}

We performed all studies near the village of Merida, on Ometepe Island, Nicaragua (co-ordinates: $11^{\circ} 25^{\prime} 12.6^{\prime \prime} \mathrm{N}, 85^{\circ} 32^{\prime} 41.5^{\prime \prime} \mathrm{W}$ ) during the dry season (March 2010) in a mixed forest-agricultural landscape. The region is characterized by dry tropical forest and volcanic soils, and typical tree genera include Guazuma (Malvaceae), Psidium (Myrtaceae), Solanum (Solanaceae), Cecropia (Urticaceae), Bursera (Burseraceae) and Vachellia (Fabaceae). Vachellia collinsii in the area are typically colonized by one of two ant genera, Pseudomyrmex spp. or Crematogaster spp. Voucher specimens of $P$. spinicola from our studies were deposited in the Colorado Plateau Museum of Arthropod Biodiversity (Flagstaff, AZ, USA). Pseudomyrmex spinicola is an obligate inhabitant of acacia thorns in Central America, as are $P$. ferruginea, $P$. nigrocincta and $P$. flavicornis (all Hymenoptera: Formicidae) (Janzen, 1966), which are also common to the study area. All work reported here took place on the south-eastern aspect of the island.

\section{Tree traits and ant responses to disturbance}

Prior to commencing our studies, we established a length distribution for branches of $V$. collinsii by measuring the lengths of all branches on 39 randomly selected trees $(n=295$ branches in total). Branch lengths were skewed in their distribution, and $75 \%$ of branch lengths were $\leq 50 \mathrm{~cm}$ (Fig. 1).

We used this knowledge of branch length distribution to select branches for measurement on randomly selected study trees, and on each study tree, we measured one branch from each of five length categories: (1) the 0th percentile (smallest branch); (2) the 25 th percentile $(\sim 10 \mathrm{~cm})$; (3) the 50th percentile $(\sim 26 \mathrm{~cm}) ;(4)$ the 75 th percentile $(\sim 45 \mathrm{~cm})$; and (5) the 100th percentile (largest branch). We also measured the diameter $(\mathrm{cm})$ of each tree at the base of the trunk flush with the ground surface (diameter at root collar (DRC)). We classified trees between 0 and $1.6 \mathrm{~cm}$ DRC as small $(0-33 \mathrm{rd}$ percentile), between 1.6 and $4.3 \mathrm{~cm}$ DRC as intermediate (34th-66th percentile) and trees $>4.3 \mathrm{~cm}$ DRC as large (67th-100th percentile). The mean height of study trees was $3.4 \mathrm{~m}( \pm 0.3 \mathrm{~m} \mathrm{SE})$. At each study tree, we also quantified forest basal area using a basal area prism and variable radius plots. 


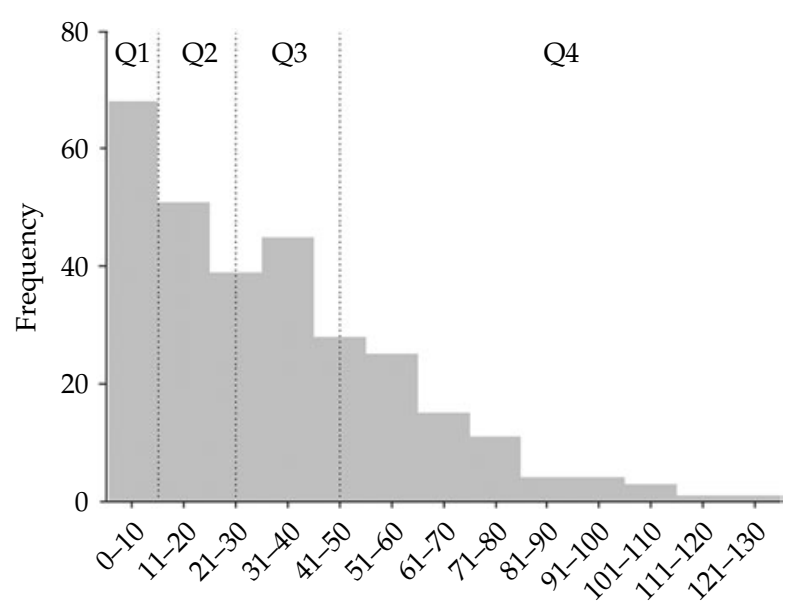

Branch length $(\mathrm{cm})$

Fig. 1. A frequency distribution histogram of branch lengths (cm) for 39 Vachellia collinsii trees ( $n=295$ branches). The dotted lines show the quartiles of the distribution (Q1: 0th-25th percentile; Q2: 26th-50th percentile; Q3: 51st75th percentile; Q4: 76th-100th percentile).

We classified areas of $<35 \mathrm{~m}^{2} /$ ha as having low basal area, $35-60 \mathrm{~m}^{2} /$ ha as medium basal area and $>60 \mathrm{~m}^{2} /$ ha as high basal area.

On each branch, we censused the number of extrafloral nectaries, food bodies, seedpods and thorns. While nectaries, food bodies and thorns are plant traits important to ant behaviours, the numbers of seedpods may represent plant fitness. We performed a visual census of the number of ants patrolling each branch prior to disturbance (Agrawal, 1998; Gaume and McKey, 1999). We then experimentally disturbed each branch by lightly shaking the branch for $5 \mathrm{~s}$ from the distal end (modified from Palmer and Brody, 2007), and we counted the number of ants recruited to the branch for 2 min. Multiple observers counted ants, and we averaged the counts from each observer. Each experimental disturbance was performed separately, and we allowed ants to return to a patrolling state between each trial (usually $\sim 5-7 \mathrm{~min}$ ). Previous studies indicated that ant 'memory' of disturbance events is related primarily to residual effects of volatile emissions from damaged plant tissues (Agrawal, 1998). We divided the number of ants counted for $2 \mathrm{~min}$ following disturbance by the number of ants initially patrolling each branch to provide an estimate of per cent increase as our metric of ant response to disturbance. We averaged all ant responses and tree traits for each tree to yield tree-level mean values for numbers of nectaries, food bodies, seedpods, thorns and per cent ant increase on branches. The above measurements and ant disturbance trials were performed on a total of 33 trees inhabited by P. spinicola.

\section{Statistical analyses}

All statistical analyses assume a type I error rate of $\alpha=0.05$ and we computed all statistics using the software package JMP 8.0 (SAS Institute). We analysed tree size class (small, intermediate and large) and forest basal area class (low, medium and high) as fixed effects on the response variables of mean ant response to disturbance (per cent increase), mean number of nectaries, mean number of food bodies, mean number of seedpods and mean number of thorns on each tree. We did not test for an interaction between tree size class and basal area class since the tree size $\times$ basal area interaction was not replicated for small-diameter trees in highdensity forests. Also, we performed least-squares linear regression of per cent ant increase on DRC. Prior to statistical testing, we checked response variables for normality using a Shapiro-Wilk test, and we visually assessed residuals for homoscedasticity of variance. All responses were found to conform to these assumptions.

\section{Results}

\section{Does tree size or forest basal area affect ant response to disturbance?}

We found that the mean per cent increase in $P$. spinicola on branches following experimental disturbances was higher for large-diameter trees than for small- and intermediate-diameter trees $\left(F_{2,27}=5.153, P=0.012\right)$. The mean per cent ant increase was $1815.7 \% \pm 317$ SE (range 116-5000\%) on large-diameter trees, $867.6 \% \pm 222$ SE (range $272-2309 \%$ ) on intermediate-diameter trees and $412.0 \% \pm 352$ SE (range 176.8-738.2\%) on smalldiameter trees. Tree diameter was positively correlated with mean per cent ant increase, where larger trees tended to have a higher increase in the number of ants on branches following disturbance (Fig. 2).

In contrast, forest basal area had a statistically marginal effect on per cent increase in P. spinicola on experimentally disturbed branches $\left(F_{2,27}=2.785\right.$, $P=0.078)$. The mean per cent ant increase was $1536 \% \pm 354$ SE (range 272-5000\%) in high basal area locations, $540 \% \pm 267 \mathrm{SE}$ (range $116-1500 \%$ ) in medium basal area locations and $1184 \% \pm 316$ SE (range 403-3683\%) in low basal area locations.

Are tree traits predictable by tree size or forest basal area?

The mean number of nectaries per branch on $V$. collinsii did not vary by tree size or forest basal area. Similarly, the mean number of food bodies and thorns per branch was not found to be variable across tree size or forest basal area classes. 


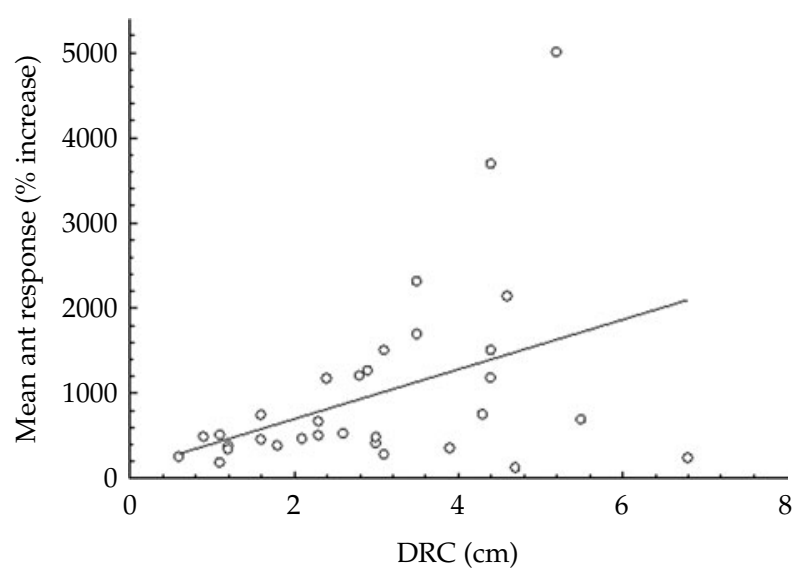

Fig. 2. A least-squares linear regression of the standardized ant response to disturbance (\% increase) on tree size (DRC). As DRC increased, so did the mean response of ants to experimental disturbances $\left(F_{1,30}=6.404 ; P=0.016\right.$; $\left.r^{2}=0.18\right)$. Equation: (mean $\%$ ant increase) $=114.56+$ 292.36 (DRC).

However, we did find that the mean number of seedpods per branch was significantly higher in areas of low basal area than in areas of medium or high basal area, while tree size class had no effect on the mean number of seedpods per branch (refer to Table 1 for statistical summary). In addition, we found no correlation between tree DRC and forest basal area $\left(F_{1,30}=0.421, P=0.521, r^{2}=0.013\right)$.

\section{Discussion}

Our studies support the hypothesis that tree size (V. collinsii) is correlated with ant ( $P$. spinicola) behavioural responses to disturbance in an antacacia system, but not forest basal area. We found that as tree DRC increased, so did the relative number of ants that responded to disturbances (Fig. 2). This finding suggests that ant responses to minor disturbances (surrogate herbivore-mediated responses) are not equivalent across a gradient of tree sizes. This should be tested with other obligate plant-ants as well, as there is evidence from African ecosystems that ants vary in their effectiveness as deterrents to herbivores (Martins, 2010). While both arthropod and mammalian herbivores likely exert pressure on acacias in the neotropics, our experimental disturbances probably most closely resembled disturbance by browsing ungulates. Conversely, forest basal area exhibited, at best, a statistically marginal correlation with ant responses. However, the variance we observed in ant responses across forest basal areas could potentially correspond to practical ecological consequences for acacias growing in forests of differing

Table 1. ANOVA summary of the effects of tree size and forest basal area on the means of four functional tree traits

\begin{tabular}{|c|c|c|c|c|c|c|}
\hline Tree trait & Factor & Level & Mean \pm SE & $F$ & $\mathrm{df}$ & $P$ \\
\hline \multirow[t]{6}{*}{ No. of nectaries/branch } & \multirow[t]{3}{*}{ Tree size } & Small & $20.30 \pm 3.80$ & \multirow[t]{3}{*}{2.247} & \multirow[t]{3}{*}{2,27} & \multirow[t]{3}{*}{0.125} \\
\hline & & Intermediate & $22.19 \pm 2.41$ & & & \\
\hline & & Large & $29.65 \pm 3.43$ & & & \\
\hline & \multirow[t]{3}{*}{ Basal area } & Low & $24.58 \pm 3.17$ & \multirow[t]{3}{*}{0.888} & \multirow[t]{3}{*}{2,27} & \multirow[t]{3}{*}{0.423} \\
\hline & & Medium & $26.91 \pm 2.58$ & & & \\
\hline & & High & $20.65 \pm 3.78$ & & & \\
\hline \multirow[t]{6}{*}{ No. of food bodies/branch } & \multirow[t]{3}{*}{ Tree size } & Small & $3.58 \pm 0.99$ & \multirow[t]{3}{*}{1.963} & \multirow[t]{3}{*}{2,27} & \multirow[t]{3}{*}{0.160} \\
\hline & & Intermediate & $1.33 \pm 0.63$ & & & \\
\hline & & Large & $1.45 \pm 0.89$ & & & \\
\hline & \multirow[t]{3}{*}{ Basal area } & Low & $2.56 \pm 0.83$ & \multirow[t]{3}{*}{0.692} & \multirow[t]{3}{*}{2,27} & \multirow[t]{3}{*}{0.509} \\
\hline & & Medium & $2.02 \pm 0.67$ & & & \\
\hline & & High & $0.91 \pm 0.98$ & & & \\
\hline \multirow[t]{6}{*}{ No. of seedpods/branch } & \multirow[t]{3}{*}{ Tree size } & Small & $1.54 \pm 1.05$ & \multirow[t]{3}{*}{0.663} & \multirow[t]{3}{*}{2,27} & \multirow[t]{3}{*}{0.524} \\
\hline & & Intermediate & $0.75 \pm 0.66$ & & & \\
\hline & & Large & $1.33 \pm 1.05$ & & & \\
\hline & \multirow[t]{3}{*}{ Basal area } & Low & $2.90 \pm 0.88 a$ & \multirow[t]{3}{*}{3.794} & \multirow[t]{3}{*}{2,27} & \multirow[t]{3}{*}{0.035} \\
\hline & & Medium & $0.26 \pm 0.71 b$ & & & \\
\hline & & High & $0.69 \pm 1.04 b$ & & & \\
\hline \multirow[t]{6}{*}{ No. of thorns/branch } & \multirow[t]{3}{*}{ Tree size } & Small & $17.17 \pm 5.14$ & \multirow[t]{3}{*}{2.247} & \multirow[t]{3}{*}{2,27} & \multirow[t]{3}{*}{0.125} \\
\hline & & Intermediate & $22.78 \pm 3.25$ & & & \\
\hline & & Large & $29.88 \pm 4.64$ & & & \\
\hline & \multirow[t]{3}{*}{ Basal area } & Low & $19.50 \pm 4.29$ & 0.866 & 2,27 & 0.432 \\
\hline & & Medium & $25.31 \pm 3.49$ & & & \\
\hline & & High & $23.13 \pm 5.11$ & & & \\
\hline
\end{tabular}

Significant effects are shown in bold, and letters show separation of means using Tukey's HSD test. 
structural types. Surprisingly, mean ant responses were highest in locations with low and high basal areas, and substantially lower in areas of medium basal area. This could indicate that acacias in forested areas of medium basal area $\left(35-60 \mathrm{~m}^{2} / \mathrm{ha}\right.$ ) may be more susceptible to herbivore damage than in areas of low $\left(<35 \mathrm{~m}^{2} / \mathrm{ha}\right)$ or high basal area (>60 $\mathrm{m}^{2} / \mathrm{ha}$ ).

One hypothesis to explain the result we report for ant behaviours is related to ant colony size. Large trees have more domatia than small trees, and may simply house more ants per unit area than smaller trees. Previous research has demonstrated that ant colony size is a critical factor in shaping ant behaviours (Palmer, 2004). However, the mean number of domatia per branch was standardized to branch length, and we did not observe that a significant difference in the mean number of domatia per branch was attributable to tree size. Thus, we did not expect a disproportionately greater response in the per cent increase of $P$. spinicola following experimental disturbances. So, although tree morphology and functional traits were conserved across tree size classes, ant responses to disturbance were not. Alternatively, there may be correlations between ant colony aggression, colony condition, and colony size or structure that would account for the differences we observed in ant responses across tree size class (Fonseca, 1993). For example, large trees might support healthier or more aggressive ant colonies than small trees, since larger trees could conceivably provide resident ant colonies with a greater abundance of resources or nesting space. Also, there is evidence from other studies to suggest that colonies of Pseudomyrmex spp. can be polygynous (Kautz et al., 2009), which could contribute to localized variations in colony behaviours. However, it is generally thought that $P$. spinicola colonies are monogynous (Ward, 1993), so a multiple-queen hypothesis is improbable to explain our results.

Our results do not support the hypothesis that functional myrmecophyte traits vary across gradients of tree size or forest basal area. Three myrmecophyte traits related to the ant-plant interaction (nectaries, food bodies and domatia) did not vary across tree size or forest basal area classes, although we did observe an increase in the mean numbers of seedpods per branch on trees in locations with low basal area. Factors mediating seed production in $V$. collinsii and other similar antplants deserve further attention, and should be assessed over standardized time intervals. We found that trees in low basal area conditions had approximately 11.1 and 4.2 times as many seedpods per branch, on average, than trees in medium and high basal area conditions, respectively (Table 1). Previous studies showed that plant volatiles cause ants to generally avoid inflorescences, and it has been proposed that ants may not directly contribute to seed-set as a result (Ghazoul, 2001). Furthermore, seedpod production can be entirely independent of ant colony defensive behaviours (Palmer and Brody, 2007), and we predict that local environmental factors (sun exposure and inter-tree competition) and phenology regulate seedpod production to a greater extent than ant behaviours.

Basal area is a widely used forest management measurement that is correlated with many environmental factors, and forest basal area could alter various aspects of ant-plant mutualisms. For example, Davidson and Fisher (1991) demonstrated that light regime mediates interactions between a myrmecophytic Cecropia sp. and resident ants. In tropical forests, light availability is strongly related to forest basal area (Montgomery and Chazdon, 2001). Similarly, environmental factors that promote or inhibit the performance of $V$. collinsii are likely to indirectly influence $P$. spinicola colonies, and these factors may be predictable by forest basal area. An assessment of specific environmental factors associated with varying levels of forest basal area and their influences on neotropical tree traits would be useful for a broad-spectrum evaluation of microsite conditions and tree morphologies.

\section{Conclusion}

Our studies argue that ant responses to disturbance are variable across a gradient of tree sizes in a neotropical ant-plant association, but forest basal area was not correlated with ant responses. Also, we found no evidence to suggest that tree functional traits ( $V$. collinsii) that relate to mutualism maintenance respond to variation in tree size or forest basal area, although we did observe significantly more seedpods on trees in low-density areas. Thus, the quantities of nectaries, food bodies and domatia appear to be uniformly distributed on $V$. collinsii in the region we surveyed, and the expression of functional traits was conserved across tree size classes. It is possible that the variation we detected in ant responses due to tree size was related to ant colony size or some other ecological factor. However, future studies of ant behaviour in ant-myrmecophyte associations should consider tree size as a factor that may introduce variation to observations of ant behaviours.

\section{Acknowledgements}

The authors are grateful for the assistance of Y. Ortiz and R. Molina, and the staff of the Ometepe Biological Field Station. K. London and R. Hofstetter provided several iterations of review and commentary for this manuscript. Funding for this study was 
provided by a Hooper grant to N.E. Foote, an N.S.F. I.G.E.R.T. fellowship to T.S. Davis, and an S.F. A.Z. fellowship to K.C. Grady. We also appreciate the efforts of two anonymous reviewers who provided helpful comments on this manuscript.

\section{References}

Agrawal A. A. (1998) Leaf damage and associated cues induce aggressive ant recruitment in a neotropical ant-plant. Ecology 79, 2100-2112.

Agyeman V. K. (1994) Environmental influences on tropical tree seedling growth. $\mathrm{PhD}$ thesis. University of Aberdeen, UK. 224 pp.

Barton A. M. (1986) Spatial variation in the effect of ants on an extrafloral nectary plant. Ecology 67, 495-504.

Beattie A. J. (1985) The Evolutionary Ecology of Ant-Plant Mutualisms. Cambridge University Press, Cambridge, England. 196 pp.

Bella I. E. (1971) A new competition model for individual trees. Forest Science 17, 364-372.

Belt T. (1874) The Naturalist in Nicaragua. E. Bumpas, London. 403 pp.

Bergh J., Linder S., Lundmark T. and Elfving B. (1999) The effect of water and nutrient availability on the productivity of Norway spruce in northern and southern Sweden. Forest Ecology and Management 119, $51-62$.

Bronstein J. (1998) The contribution of ant-plant protection studies to our understanding of mutualism. Biotropica 30, 150-161.

Davidson D. W. and Fisher B. L. (1991) Symbiosis of ants with Cecropia as a function of light regime, pp. 289-309. In Ant-plant Interactions (edited by C. R. Huxley and D. F. Cutler). Oxford University Press, Oxford.

Davidson D. W., Snelling R. R. and Longino J. T. (1989) Competition among ants for myrmecophytes and the significance of plant trichomes. Biotropica 21, 64-73.

D'Souza L. E., Reiter M., Six L. J. and Bilby R. E. (2011) Response of vegetation, shade, and stream temperature to debris torrents in two western Oregon watersheds. Forest Ecology and Management 261, 2157-2167.

Fonseca C. R. (1993) Nesting space limits colony size of the plant-ant Pseudomyrmex concolor. Oikos 67, $473-482$.

Gaume L. and McKey D. (1999) An ant-plant mutualism and its host-specific parasite: activity rhythms, young leaf patrolling, and effects on herbivores of two specialist plant-ants inhabiting the same myrmecophyte. Oikos 84, 130-144.

Ghazoul J. (2001) Can floral repellants pre-empt potential ant-plant conflicts? Ecology Letters 4, 295-299.

Heil M. and McKey D. (2003) Protective ant-plant interactions as model systems in ecological and evolutionary research. Annual Review of Ecology, Evolution and Systematics 34, 425-453.
Janzen D. H. (1966) Coevolution of mutualism between ants and acacias in Central America. Evolution 20, 249-275.

Janzen D. H. (1973) Dissolution of mutualism between Cecropia and its Azteca ants. Biotropica 5, 15-28.

Kautz S., Pauls S. U., Ballhorn D. J., Lumbsch H. T. and Heil M. (2009) Polygynous supercolonies of the acacia-ant Pseudomyrmex peperi, an inferior colony founder. Molecular Ecology 18, 5180-5194.

Martins D. J. (2010) Not all ants are equal: obligate acacia ants provide different levels of protection against mega-herbivores. African Journal of Ecology 48, $1115-1122$.

Montgomery R. A. and Chazdon R. L. (2001) Forest structure, canopy architecture, and light transmittance in tropical wet forests. Ecology 82, 2707-2718.

Palmer T. M. (2003) Spatial habitat heterogeneity influences competition and coexistence in an African ant-acacia guild. Ecology 84, 2843-2855.

Palmer T. M. (2004) Wars of attrition: colony size determines competitive outcomes in a guild of African acacia ants. Animal Behavior 68, 993-1004.

Palmer T. M. and Brody A. K. (2007) Mutualism as reciprocal exploitation: African plant-ants defend foliar but not reproductive structures. Ecology 88, 3004-3011.

Palmer T. M., Stanton M. L., Young T. P., Goheen J. R., Pringle R. M. and Karban R. (2008) Breakdown of an ant-plant mutualism follows the loss of large herbivores from an African savanna. Science 319, 192-195.

Phillips O. L., Malhi Y., Higuchi N., Laurance W. F., Núñez P. V., Vásquez R. M., Laurance S. G., Ferreira L. V., Stern M., Brown S. and Grace J. (1998) Changes in the carbon balance of tropical forests: evidence from long-term plots. Science 282, 439-442.

Poorter L. (1999) Growth responses of 15 rain-forest tree species to a light gradient: the relative importance of morphological and physiological traits. Functional Ecology 13, 396-410.

Rico-Gray V., Garcia-Franco J. G., Palacios-Rios M., DiazCastelazo M., Parra-Tabla V. and Navarro J. A. (1998) Geographical and seasonal variation in the richness of ant-plant interactions in Mexico. Biotropica 30, 190-200.

Rosati A., Esparza G., DeJong T. M. and Pearcy R. W. (1999) Influence of canopy light environment and nitrogen availability on leaf photosynthetic characteristics and photosynthetic nitrogen use efficiency of field grown nectarine trees. Tree Physiology 19, 173-180.

Ward P. S. (1993) Systematic studies on Pseudomyrmex acacia ants (Hymenoptera: Formicidae: Pseudomyrmecinae). Journal of Hymenoptera Research 2, 117-168.

Willmer P. G. and Stone G. N. (1997) How aggressive antguards assist seed-set in Acacia flowers. Nature 388, $165-167$. 